\title{
Interaction of ozone and organic matter in coagulation with inorganic polymer flocculant-PACl: Role of organic components
}

\author{
Hailong Liu ${ }^{\mathrm{a}, \mathrm{b}, *}$, Fangqin Cheng ${ }^{\mathrm{a}}$, Dongsheng Wang ${ }^{\mathrm{b}, 1,2}$ \\ a School of Environmental Sciences and Resources, Shanxi University, Taiyuan 030002, China \\ b State Key Laboratory of Environmental Aquatic Chemistry, Research Center for Eco-Environmental Science, Chinese Academy of Sciences, Box 2871, Beijing 100085, China
}

\section{A R T I C L E I N F O}

Article history:

Accepted 30 June 2008

Available online 4 October 2009

Keywords:

Pre-ozonation

Enhanced coagulation

AOM

Fractionation

Humic acid

\begin{abstract}
A B S T R A C T
In this study, two model waters were used to evaluate the ozone effect on aquatic organic matter (AOM) removal by coagulation with inorganic polymer flocculant (IPF)-polyaluminum chloride ( $\mathrm{PACl}$ ). Flocs formation during coagulation processes were detected by using PDA (Photometric Dispersion Analyzer). Apparent molecular weight distribution (AMWD) and resin fractionation (RF) were also performed to characterize the change of $A O M$ as a result of pre-ozonation. The experimental results show that the dosage of $\mathrm{O}_{3}$, characteristics and composition of AOM are the most important factors on the behavior of coagulation. Great differences have been found between the two model waters. Coagulation in model water 1 (MW1) (composed of humic acids) is impaired markedly by pre-ozonation, as more DOC (Dissolved Organic Carbon) is produced with increasing $\mathrm{O}_{3}$ dosage. Floc formation, as exhibited from decreasing of the slopes of FI (Flocculation Index), is retarded gradually during coagulation process. Although residual turbidity is reduced with $1.15 \mathrm{mg} / \mathrm{L} \mathrm{O}_{3}$, removals of DOC and $\mathrm{UV}_{254}$ all decreased. As for model water 2 (MW2) (composed of salicylic acid), FI is retarded also, but turbidity and DOC removals of coagulation after pre-ozonation are improved to a certain extent. Coagulation performance judged from removal of DOC is improved distinctly by pre-ozonation. Fractionation results show that molecular weight of organic matter (OM) of MW1 is converted from higher to lower; and OM becomes from more hydrophobic to more hydrophilic, which might be one of the mechanisms involved in the impairment of ozonation on coagulation effect. OM in MW2 is oxidized and mineralized to a greater extent, thus its impairment on coagulation is released. Finally, according to water properties, some proposed applications were provided for application of ozone in water treatment process.
\end{abstract}

(c) 2009 Elsevier B.V. All rights reserved.

\section{Introduction}

Ozone is widely used in drinking water treatment nowadays. Preozonation has profound influences on particle stability and TOC (total organic carbon) removal. Although complicated effects of $\mathrm{O}_{3}$ on organic matter coagulation were widely reported [1-7], proper mechanisms involved in the influence of ozone in coagulation processes still lagged far behind ozonation utility.

The oxidation of organic and inorganic compounds in water by ozone along with its secondary oxidant $(\bullet \mathrm{OH}$ radicals) changed the components of the subject water significantly [8]. Reckhow [9] reported that $\mathrm{UV}_{254}$ and TOC, TOX (total organic halogen) could be significantly reduced after pre-ozonation. And Singer [10] suggested the dosage of pre-ozonation for best coagulation was between 0.4 and $0.8 \mathrm{mg} \mathrm{O}_{3} / \mathrm{mg}$

\footnotetext{
* Corresponding author. WuCheng Road No. 92, Taiyuan, Shanxi Province, 030002, China. Tel.: +86 351 7016893; fax: +86 3517016893 .

E-mail addresses: hlliu827@yahoo.com.cn (H. Liu), lduo1598@yahoo.com.cn (D. Wang).

${ }^{1}$ Mail address: Shuangqing Road No. 18, Haidian District, Beijing, 100085, China.

2 Tel.: +86 10 62849138; fax: +861064953157.
}

carbons and ozone worked as coagulant-aid. But as Tobiason [11] pointed out that when alum was used, ozonation decreased the turbidity with no coagulant; pre-ozonation could not reduce the dosage of coagulant. At the dosage of $1 \mathrm{mg} \mathrm{O}_{3} / \mathrm{mg} \mathrm{DOC}$, a slight decrease of DOC removal was observed. Selcuk and his colleagues $[1,2]$ investigated the effect of pre-ozonation on aluminum sulphate (alum) and polyaluminum chloride (PACl) on raw waters collected from Omerli, Buyukcekmece and Carmine in Istanbul. Results showed that pre-ozonation enhanced TOC removal and TTHMFP reduction when it was used in combination with both coagulants (alum and $\mathrm{PACl}$ ); but total haloacetic acid formation potential (THAAFP) increased after each coagulation, ozonation and their combination. They also reported that $300 \mu \mathrm{g} / \mathrm{L}$ bromide spiking in raw sample collected from Carmine increased the formation of brominated disinfection by-products from $0.4 \mu \mathrm{g} / \mathrm{L}$ to $1.2 \mu \mathrm{g} / \mathrm{L}$ after coagulation with $120 \mathrm{mg} / \mathrm{L} \mathrm{PACl}$ [1]. Some others reported that ozonation decreased molecular weight and increased hydrophilic property of Natural Organic Matter (NOM), which decreased the treatability of AOM by coagulation [4,12]. As Edwards et al. [13] complained, "Because ozonation could, in theory, either increase or decrease NOM removal by either sorption or precipitation, it is difficult to predict the overall effect of NOM behavior in a coagulation process." 
Effect of ozonation on coagulation was quite complicated and not well understood. It might result from many factors being involved in the interactions of ozone, NOM and coagulants and some of the factors were still unclear. In this paper, experiments were designed to gain further insight into the mechanism of ozone effect on coagulation. Two typical kinds of model water with different organic components, model water 1 (MW1) consisted mainly of humic acids and model water 2 (MW2) (composed mainly of salicylic acid), were prepared to give certain distribution of hydrophobic and hydrophilic organics with different particle sizes. Inorganic polymer flocculant, polyaluminum chloride $(\mathrm{PACl})$ with typical speciation distribution, was also prepared to examine the role of coagulant species; and the results were published in another article [14].

The objective of this study was to examine the importance of organic matter character change after ozonation on coagulation performance. PDA (Photometric Disperse Analyzer) was used to evaluate the difference of coagulation under influence of ozonation and the dosage effect of ozonation. Apparent molecular weight distribution and resin fractionation of the raw water, ozonized water and coagulated water were characterized to elucidate the mechanisms further.

\section{Materials and methods}

\subsection{Materials}

Water samples: HA (humic acids, Tianjin, China), GA (glutamic acid, Shanghai, China) and SA (salicylic acid, Beijing, China) were chosen as the model OM in the samples. Stock solutions of above OMs were prepared. HA represented large molecular and fairly hydrophobic OM in water. GA and SA represented smaller molecular in water [15]. Although GA and SA were not commonly found in natural water instead of fulvic acid, they were chosen because their chemical structures are much clearer than fulvic acid and their activities with ozone and coagulation are almost through the similar mechanism as DOM. Kaolin was used as model particle in water. The particle size distribution of kaolin suspension was determined by an Elzone 280 PC particle counter (Coulter Electronics Ltd., Bedfordshire, U.K.). The particles were mostly below about $5 \mu \mathrm{m}$ in size, with a mean size of about $2 \mu \mathrm{m}$. A certain amount of kaolin, humic acids and glutamic acid were mixed in tap water to build model water 1 sample (denoted as MW1). The same amount of kaolin and glutamic acid was mixed in the same tap water, but humic acids were replaced by salicylic acid to build model water 2 sample (denoted as MW2) (Table 1).

All the sample waters were kept stirring for at least $12 \mathrm{~h}$ to simulate natural properties of NOM. Some of the main parameters of the tap water and the two model waters were measured and were shown in Table 2.

Coagulant used in the study was synthesized by using a slow base titration method at room temperature $\left(18-22^{\circ} \mathrm{C}\right)$ in laboratory [16]. $\mathrm{PACl}$ used in the study had a B value (basicity) of 2.5 , and was termed $\mathrm{PACl}_{2.5}$. The synthesized $\mathrm{PACl}$ and its speciation distribution could be easily repeated following described routines.

\subsection{Methods}

\subsubsection{Ozonation and coagulation}

Ozone was generated by Ozonizer OS-IN (Mitsubishi Electric). Ozone dosage was determined through ozone-demand tests. $\mathrm{O}_{3}$ concentra-

Table 1

Components of the two model water.

\begin{tabular}{lllll}
\hline Samples & $\begin{array}{l}\text { Kaolin } \\
\left(\mathrm{mg} \mathrm{L}^{-1}\right)\end{array}$ & $\begin{array}{l}\mathrm{HA} \\
\left(\mathrm{TOC} \mathrm{mg} \mathrm{L}^{-1}\right)\end{array}$ & $\begin{array}{l}\mathrm{SA} \\
\left(\mathrm{TOC} \mathrm{mg} \mathrm{L}^{-1}\right)\end{array}$ & $\begin{array}{l}\mathrm{GA} \\
\left(\mathrm{TOC} \mathrm{mg} \mathrm{L}^{-1}\right)\end{array}$ \\
\hline MW 1 & 20 & 2.0 & 0 & 0.5 \\
MW 2 & 20 & 0 & 2.0 & 0.5 \\
\hline
\end{tabular}

Table 2

Main parameters of the tap water and the synthetic waters.

\begin{tabular}{llclll}
\hline Samples & $\begin{array}{l}\text { TOC } \\
\left(\mathrm{mg} \mathrm{L}^{-1}\right)\end{array}$ & $\begin{array}{l}\text { Turbidity } \\
(\mathrm{NTU})\end{array}$ & $\mathrm{pH}$ & $\begin{array}{l}\text { Alkalinity } \\
\left(\mathrm{mg} \mathrm{L}^{-1}\right)\end{array}$ & $\begin{array}{l}\text { Hardness } \\
\left(\mathrm{mg} \mathrm{L}^{-1}\right)\end{array}$ \\
\hline Tap water & 2.09 & 0.38 & 7.03 & 133 & 162 \\
MW 1 & 4.53 & 10.3 & 7.00 & 133 & 163 \\
MW 2 & 4.50 & 8.21 & 7.00 & 130 & 163.5 \\
\hline
\end{tabular}

tions of pre-ozonation, input gas and residual gas were measured by sulfides iodometric method [17]. $\mathrm{O}_{3}$ dosage was calibrated twice during each test. $10 \mathrm{~min}$ after ozone was introduced, samples were purged by high pressure, high pure nitrogen to eliminate residue $\mathrm{O}_{3}$ to ensure the contact time. Ozone dosage in the following study referred to contact dosage (average dosage remained in water sample during contact time).

Jar test conditions: $500 \mathrm{~mL}$ water sample was put in a $800 \mathrm{~mL}$ beak, mixed at $250 \mathrm{rpm}$ for $1 \mathrm{~min}$ after dosing of PACl as coagulant with a pipette in certain dosages designed by the following experiments, slowly mixed at $40 \mathrm{rpm}$ for $15 \mathrm{~min}$ and then settled for $10 \mathrm{~min}$. Samples were taken from $2 \mathrm{~cm}$ below the surface for further analysis. Based on the above experiments, the $\mathrm{PACl}$ doses used in pre-ozonation were chosen as $1.5 \mathrm{mg} / \mathrm{L}$ and $3.0 \mathrm{mg} / \mathrm{L}$.

Formation of flocs was detected with PDA (Photometric Disperse Analyzer, Rank Brothers LTD.). FI (Flocculation Index), the output from the PDA, was recorded from $90 \mathrm{~s}$ before the beginning of rapid mixing to the end of slow mixing. The principle of PDA has been described elsewhere [16].

All of the above experiments were repeated at least twice.

\subsubsection{Organic matter fractionations}

Certain amount of raw water ( $\mathrm{pH}$ 7.0) was filtered through $0.45 \mu \mathrm{m}$ membrane. The membrane was washed by pure water before using. The filtrate was collected and designated as DOC of the water. The filtrate passed slowly at about $200 \mathrm{~mL} / \mathrm{h}$ through a column ( $3.5 \mathrm{~cm} / 50 \mathrm{~cm}$, diameter/length) filled with certain amount $(80 \mathrm{~mL})$ of XAD-8 resin. Hydrophobic base (Hob) and hydrophobic neutral (Hon) parts of organic matter were adsorbed on the XAD-8 resin. The effluent was collected and adjusted to $\mathrm{pH} 2.0$ using $\mathrm{HCl}$ and then pumped into the second XAD- 8 column, and hydrophobic acid (Hoa) were adsorbed. The effluent from the second XAD- 8 was pumped into another column filled with XAD-4 resin, which adsorbed the weakly hydrophobic part (Who) and the effluent was collected as hydrophilic fraction $(\mathrm{Hi})$. The first XAD-8 column was eluted with $0.1 \mathrm{~mol} / \mathrm{L}$ $\mathrm{H}_{3} \mathrm{PO}_{4}$, the elution representing hydrophobic basic fraction (Hob). The residual fraction on the resin was designated as Hon. All volumes of the influents and effluents above were recorded and then DOC of all samples was detected by TOC analyzer. Mass balances conducted between column influent and effluent was, on the average, at least $90 \%$ of the OM can be accounted for by this procedure.

Apparent molecule weight distributions of samples along the traditional treatment were performed by a set of ultra-filtration device (Millipore Corp., U.S.A). Pure nitrogen was used as the pressure source to drive the filtrate at a pressure about $0.2-0.3 \mathrm{MPa}$. And the concentration factor of ultra-filtration was 6:1. Dissolved organic matters were divided into four parts: $<1 \mathrm{kDA}, 1-10 \mathrm{kDA}, 10-30 \mathrm{kDA}, 30 \mathrm{kDA}-0.45 \mu \mathrm{m}$. DOC and $U_{254}$ of each part were tested. DOC recoveries of both the above two methods were tested and reached about $90 \%-110 \%$.

\subsubsection{Analytical methods}

TOC/DOC (DOC, samples passed $0.45 \mu \mathrm{m}$ membrane) was measured by TOC Analyzer Phoenix 8000; UV $_{254}$ was measured by UV-Vis 8500 Spectrophotometer; turbidity was measured by 2100 N Turbidimeter (Hach). 


\section{Results and discussions}

\subsection{Effect of ozonation on the model water}

Different doses of ozone were used during pre-ozonation of the two model waters and the major parameters involved are summarized in Table 3.

Different trends have been found in the two model waters after ozonation. From Table 3, it can be seen that for MW1, turbidities are decreased after ozonation, while DOC and $\mathrm{UV}_{254}$ are increased with the increase of $\mathrm{O}_{3}$. Turbidities decrease with ozone increasing. For MW2, turbidities are dropped also after addition of $\mathrm{O}_{3}$, but increase gradually with the increase of $\mathrm{O}_{3}$ dosages. The DOC is decreased while $\mathrm{UV}_{254}$ to the contrary is increased with increasing $\mathrm{O}_{3}$ dose.

The results shown above indicate that the property of primary AOM plays significant role during ozonation. It was reported that HA influences the stability of aggregates effectively and decreased the rate of coagulation of small aggregates [18]. But would the influence be changed by pre-ozonation? For MW1, HA and GA dominate the AOM. HA is fairly large in molecular weight and much hydrophobic. Its particle size in solution ranges around $250 \mathrm{~nm}$ or $330 \mathrm{~nm}$, as detected using an Atomic Force Microscope (Nanoscope IIIa multimode, Digital Instruments, Santa Barbara, CA, U.S.A.). It seems HA is easily adsorbed by kaolin particle and removed during filtration. The adsorbed AOM in MW1 reaches as high as $2.38 \mathrm{mg} / \mathrm{L}$ as shown in Tables 2 and 3 (difference of TOC and DOC in raw water MW1, 4.53$2.15 \mathrm{mg} / \mathrm{L}$ ). With the addition and increase of dose of $\mathrm{O}_{3}$, the increasing DOC in MW1 indicates that ozone desorbs and/or decomposes HA from kaolin particle surface. The desorption of HA decreases partially the stability of kaolin particle as indicated from the decrease of turbidity with the increase of ozone dose. On the other hand, it seemed that $\mathrm{O}_{3}$ decolored $\mathrm{HA}$ in the samples, which reduced turbidity somewhat. Some OM is mineralized or removed completely after pre-ozonation, but the major OM is desorbed and decomposed resulting in increased DOC and $\mathrm{UV}_{254}$ after ozonation. This is further supported by the AOM fractionation analysis as addressed in the subsequent section.

For MW2, SA and GA dominate the sample water AOM. The particle size and molecule are markedly smaller than HA in MW1. Although TOC of both model waters is the same (Table 2), DOC component distributions are quite different (details in the following Section 3.3). The adsorbed AOM (difference of TOC and DOC in raw water MW2, $4.50-3.72 \mathrm{mg} / \mathrm{L}$ ) in this case (MW2) is only $0.78 \mathrm{mg} / \mathrm{L}$ (Tables 2, 3). However, SA and GA being small molecules are easily oxidized by $\mathrm{O}_{3}$ and exhibit some dose-effect relationship. DOC is decreased with increasing $\mathrm{O}_{3}$ doses. However, the extent of mineralization is still limited. The results correspond also well with the literature [19]. The increase of $\mathrm{UV}_{254}$ with ozonation might be due to the contribution of AOM in the tap water used. And structures of some molecules incapable of adsorbing UV at $254 \mathrm{~nm}$ are changed to be capable of adsorbing the $254 \mathrm{~nm}$ UV after ozonation was judged by the above results.

Table 3

Characteristics of the two model water after ozonation.

\begin{tabular}{lllll}
\hline Samples & $\mathrm{O}_{3}\left(\mathrm{mg} \mathrm{L}^{-1}\right)$ & Turbidity (NTU) & $\mathrm{UV}_{254}\left(\mathrm{~cm}^{-1}\right)$ & $\mathrm{DOC}\left(\mathrm{mg} \mathrm{L}^{-1}\right)$ \\
\hline MW 1 & 0.00 & 10.30 & 0.0580 & 2.15 \\
& 1.15 & 10.20 & 0.0701 & 2.31 \\
& 2.40 & 9.78 & 0.0721 & 2.40 \\
& 3.80 & 9.19 & 0.0859 & 2.84 \\
MW 2 & 0.00 & 8.30 & 0.0205 & 3.72 \\
& 1.15 & 7.38 & 0.0429 & 3.65 \\
& 2.40 & 7.75 & 0.0525 & 3.56 \\
& 3.80 & 7.87 & 0.0642 & 3.36 \\
\hline
\end{tabular}

\subsection{Effect of pre-ozonation on coagulation with $\mathrm{PACl}$}

Coagulation of the two model waters was performed using $\mathrm{PACl}_{2.5}$. Flocculation Index (FI) was recorded using PDA. The results are shown in Figs. 1 and 2 and Table 4. From Fig. 1, it is obvious that a much steeper slope and a higher plateau are observed in FI curves of MW1 than that of MW2 at a $\mathrm{PACl}$ dosage of $1.5 \mathrm{mg} \mathrm{Al} \mathrm{O}_{3} / \mathrm{L}$. It indicates that flocs formed in MW1 are faster and steadier than in MW2. The average floc diameter of MW1 is larger than MW2. The difference is due to the difference of the AOM components, humic acid and salicylic acid, in the two model waters. Although TOC of humic acid and salicylic acid in the model water is almost the same, their coagulant demand is markedly different. Salicylic acid being small molecule and hydrophilic needs large quantity of coagulant to reach charge-neutralization and certain destabilization. The trend is also observed at higher coagulant dosage $(3.0 \mathrm{mg} / \mathrm{L})$ except the difference becomes less significant, although the slopes of FI curves of both model waters are steeper than in the lower dosage ones.

The effect of ozone dosages on coagulation of the model water is further carried out with $\mathrm{PACl}_{2.5}$ at a dose of $1.5 \mathrm{mg} / \mathrm{L}$. The FI results are recorded in Fig. 2. For MW1, the growth of FI seems not be interfered with $\mathrm{O}_{3}$ at dosages less than $2.4 \mathrm{mg} / \mathrm{L}$. The final plateau reached however defers a little and floc sizes seem increased slightly under $\mathrm{O}_{3}$ $1.15-2.4 \mathrm{mg} / \mathrm{L}$. In MW2, the slopes of FI drop with the increase of $\mathrm{O}_{3}$, which indicates the rate of floc formation is lowered markedly according to the dosages of ozone. The plateaus are steadier and slightly higher than the case with absent ozone, which shows floc formed during coagulation becomes more stable for the reduction of
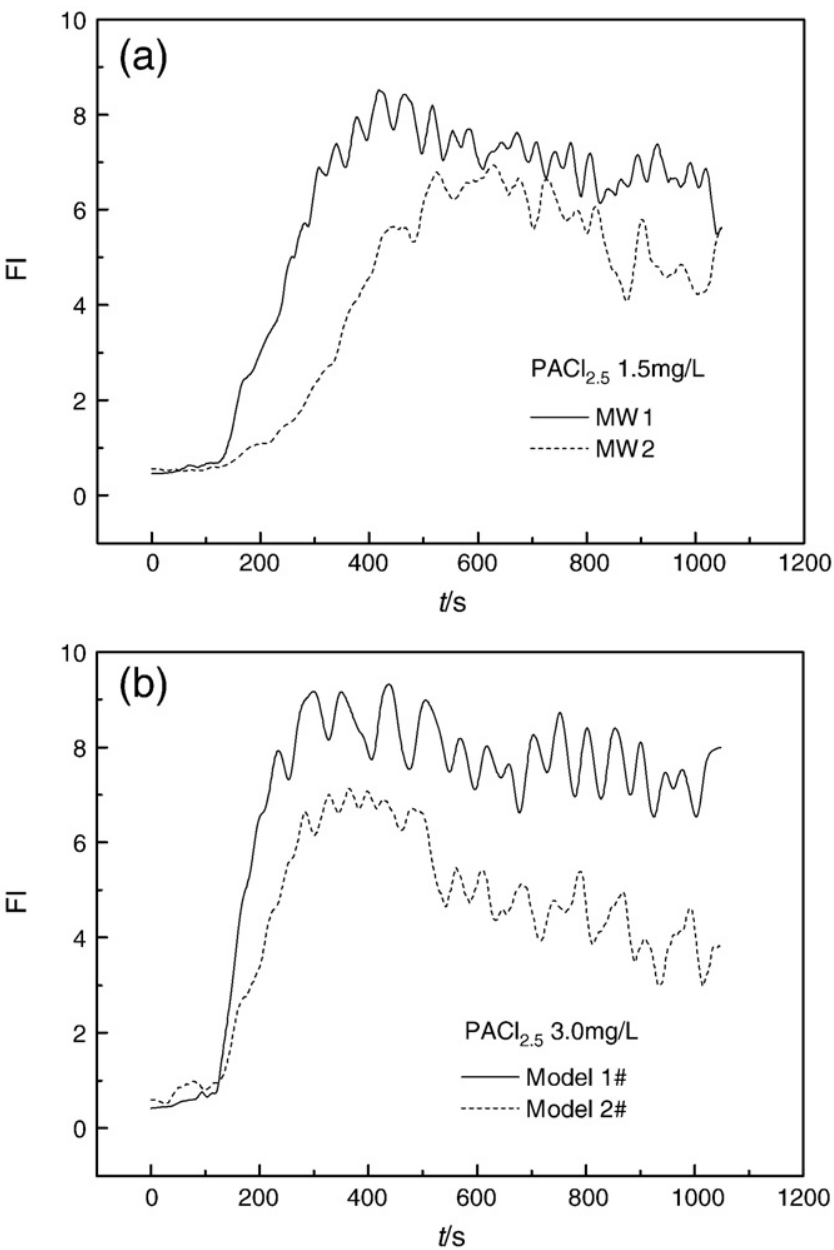

Fig. 1. FI of different waters coagulation. 

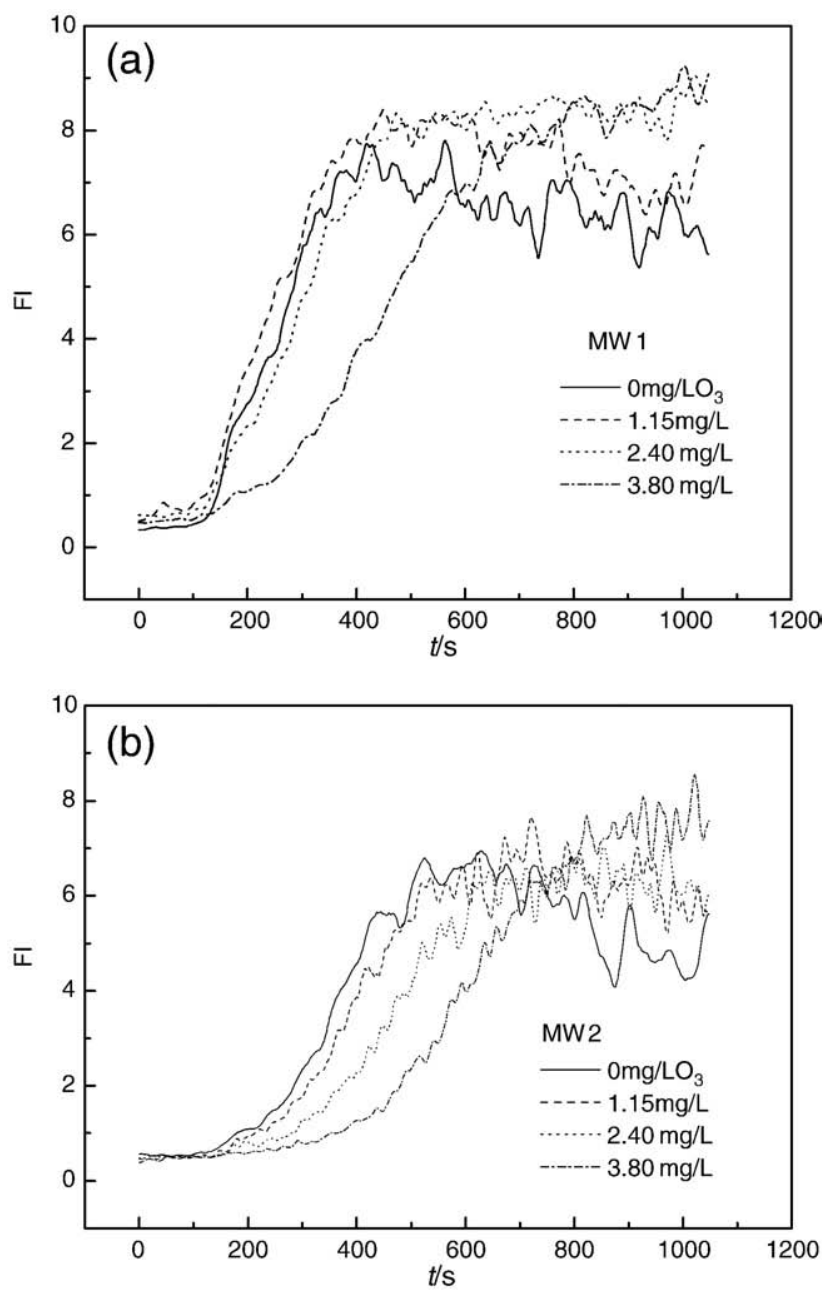

Fig. 2. Impacts of ozone at different dosages.

DOM by oxidation process. The result is proved further by residual turbidity in Table 4.

Results of coagulation after pre-ozonation with different $\mathrm{O}_{3}$ dosages are shown in Table 4. For a clear comparison, the data of DOC and UV absorption before coagulation are also listed. Distinct trends have been observed for the two model waters. With the increase of $\mathrm{O}_{3}$ dosage, the residual turbidities (RT) of MW1 increase except that at relatively low $\mathrm{O}_{3}$ dosage $(1.15 \mathrm{mg} / \mathrm{L})$ shows somewhat coagulation-aid effects. However, the DOC as well as $\mathrm{UV}_{254}$ keeps increasing with the increase of $\mathrm{O}_{3}$ dosages. It indicates that ozone interacts with HA in MW1 resulting in desorption and decomposition of HA which increases the coagulant demand significantly. The decomposed products might function as bridge-effect during coagulation and improve the formation of flocs. Organic coatings on particles are destroyed by ozonation, which destabilizes particles by reducing steric and electrostatic barriers [20]. With increasing $\mathrm{O}_{3}$ dosages, the coagulation-aid effect disappears gradually as the molecule became more and more small with ozonation and bridgeeffect could no longer exist. It seems the portion of DOM with higher UV254 abs is easier to remove by coagulation with PACl. The removal rate of $\mathrm{UV}_{254}$ could be as large as $70 \%$. However, with the increase of ozone dose, the removal rate decreases gradually to $62 \%, 57 \%$ and $50 \%$. Increasing the dose of coagulant, the phenomena are the same except that each removal rate accordingly is increased.

For MW2, similar trends of coagulation-aid phenomena of preozonation and change of RT are observed in FI (Fig. 2b). As shown previously, the component of the MW2 is mainly hydrophilic small molecule salicylic acid; no coagulation-aid effect as that of MW1 mentioned above could be yielded. The improved floc formation as observed by PDA in low $\mathrm{O}_{3}$ dose might be due to ozonation and decomposition of the primary AOM in the tap water. Contrary to MW1, DOC of MW2 exhibits a readily decrease with $\mathrm{O}_{3}$ dosage. It indicates that small AOM could be efficiently mineralized by $\mathrm{O}_{3}$ or its secondary oxidant, hydroxyl radical $(\cdot \mathrm{OH})$.

The change of specific UV absorption value (SUVA $=100 * \mathrm{UV}_{254} /$ DOC) before coagulation and after coagulation is also shown in Table 4. For MW1, it is interesting to note that ozone reacts with HA resulting in mainly desorption of HA from adsorbed kaolin particle as indicated by the little change of SUVA around $3.0 \mathrm{~m}^{-1} \mathrm{mg}^{-1} \mathrm{~L}$ at various ozone dosages. While the SUVA after coagulation increases markedly from $1.12 \mathrm{~m}^{-1} \mathrm{mg}^{-1} \mathrm{~L}$ to $1.82 \mathrm{~m}^{-1} \mathrm{mg}^{-1} \mathrm{~L}$, which indicates that ozonation increases coagulant demand and the treatability of the AOM in the water sample by coagulation is still remarkable [21]. For MW2, the SUVA increases lineally with the increase of ozone dose with some change of DOC removal before and after coagulation. It indicates that ozonation results in mineralization of the small molecule salicylic acid as shown from the decrease of DOC from initial $3.76 \mathrm{mg} / \mathrm{L}$ to $3.36 \mathrm{mg} / \mathrm{L}$ at the highest dose investigated. Furthermore, the primary AOM in the tap water becomes much more treatable after ozonation as indicated by the increase of SUVA from the $0.5 \mathrm{~m}^{-1} \mathrm{mg}^{-1} \mathrm{~L}$ to $1.9 \mathrm{~m}^{-1} \mathrm{mg}^{-1} \mathrm{~L}$, which increases again coagulant demand.

Table 4

Results of coagulation after pre-ozonation.

\begin{tabular}{|c|c|c|c|c|c|c|c|c|c|}
\hline $\mathrm{PACl}$ & Water & $\mathrm{O}_{3}\left(\mathrm{mg} \mathrm{L}^{-1}\right)$ & Turb. (NTU) & $\mathrm{UV}_{254}\left(\mathrm{~cm}^{-1}\right)$ & $\mathrm{DOC}\left(\mathrm{mg} \mathrm{L}^{-1}\right)$ & SUVA $\left(\mathrm{m}^{-1} \mathrm{mg}^{-1} \mathrm{~L}\right)$ & $\mathrm{UV}_{0}^{*}\left(\mathrm{~cm}^{-1}\right)$ & $\mathrm{DOC}_{0}^{*}\left(\mathrm{mg} \mathrm{L}^{-1}\right)$ & SUVA $^{*}\left(\mathrm{~m}^{-1} \mathrm{mg}^{-1} \mathrm{~L}\right)$ \\
\hline \multirow[t]{8}{*}{$1.5 \mathrm{mg} \mathrm{L}^{-1}$} & MW 1 & 0 & 1.61 & 0.0183 & 1.64 & 1.12 & 0.0580 & 2.15 & 2.70 \\
\hline & MW 1 & 1.15 & 1.48 & 0.0271 & 1.81 & 1.50 & 0.0701 & 2.31 & 3.03 \\
\hline & MW 1 & 2.40 & 1.76 & 0.0310 & 1.88 & 1.65 & 0.0721 & 2.40 & 3.00 \\
\hline & MW 1 & 3.80 & 3.31 & 0.0426 & 2.34 & 1.82 & 0.0859 & 2.84 & 3.02 \\
\hline & MW 2 & 0 & 1.21 & 0.0193 & 3.52 & 0.55 & 0.0205 & 3.72 & 0.55 \\
\hline & MW 2 & 1.15 & 1.14 & 0.0374 & 3.45 & 1.08 & 0.0429 & 3.65 & 1.18 \\
\hline & MW 2 & 2.40 & 1.16 & 0.0455 & 3.33 & 1.37 & 0.0525 & 3.56 & 1.47 \\
\hline & MW 2 & 3.80 & 1.32 & 0.0582 & 3.03 & 1.92 & 0.0642 & 3.36 & 1.91 \\
\hline \multirow[t]{8}{*}{$3.0 \mathrm{mg} \mathrm{L}^{-1}$} & MW 1 & 0 & 1.18 & 0.0170 & 1.45 & 1.17 & 0.0580 & 2.15 & 2.70 \\
\hline & MW 1 & 1.15 & 0.85 & 0.0206 & 1.63 & 1.26 & 0.0701 & 2.31 & 3.03 \\
\hline & MW 1 & 2.40 & 1.76 & 0.0222 & 1.81 & 1.23 & 0.0721 & 2.40 & 3.00 \\
\hline & MW 1 & 3.80 & 2.33 & 0.0308 & 2.10 & 1.47 & 0.0859 & 2.84 & 3.02 \\
\hline & MW 2 & 0 & 0.73 & 0.0177 & 3.49 & 0.51 & 0.0205 & 3.72 & 0.55 \\
\hline & MW 2 & 1.15 & 0.67 & 0.0362 & 3.46 & 1.05 & 0.0429 & 3.65 & 1.18 \\
\hline & MW 2 & 2.40 & 0.76 & 0.0445 & 3.26 & 1.37 & 0.0525 & 3.56 & 1.47 \\
\hline & MW 2 & 3.80 & 0.68 & 0.0564 & 2.97 & 1.90 & 0.0642 & 3.36 & 1.91 \\
\hline
\end{tabular}

Parameters with “*”: sample collected before coagulation. 


\subsection{AOM RA fractionation and molecular weight} distribution characterization

Pre-ozonated waters at different ozone doses were coagulated using $\mathrm{PACl}$ at $3.0 \mathrm{mg} / \mathrm{L}$ under the same condition described above. Samples before and after ozonation, and the settled water after coagulation as well were further characterized using ultra-filtration (UF) and resin absorption (RA) fractionation methods. The results are partially shown in Figs. 3-6.

From Fig. 3a, it can be seen that DOC of MW1 increases with the increase of $\mathrm{O}_{3}$ dose. The apparent molecular weight distribution of the increased DOC is markedly changed with the increase of $\mathrm{O}_{3}$ dose. As observed, the 1-10 kDa fraction increases markedly. While the smallest fraction $<1 \mathrm{kDA}$ is increased first and then decreases with further addition of ozone. It is indicative that ozone reacts with the AOM results in decomposition of the large molecule AOM to moderate and finally small ones. After coagulation (Fig. 3b), the AOM without ozonation is markedly removed for the various molecule fractions. The largest molecule fractions experienced pre-ozonation seem much easier to be removed, while the smallest fractions remain. The assumption of decomposing and desorbing OM from adsorbed HA is well proved.

For MW2 (Fig. 4) containing mainly salicylic acid and the AOM in the primary tap water, similar effect of ozone on the AMWD of AOM is observed. Ozone decomposes salicylic acid markedly with the increase of doses, judging from the lowering total DOC (Fig. 4a). While ozone reacts with the AOM in the primary tap water resulting in decomposition from large molecule to moderate and finally small ones. So the AMWD phenomena after pre-ozonation as MW1 are observed clearly. Results of coagulation after pre-ozonation (Fig. 4b) show that DOC is removed somewhat, and small molecular AOM
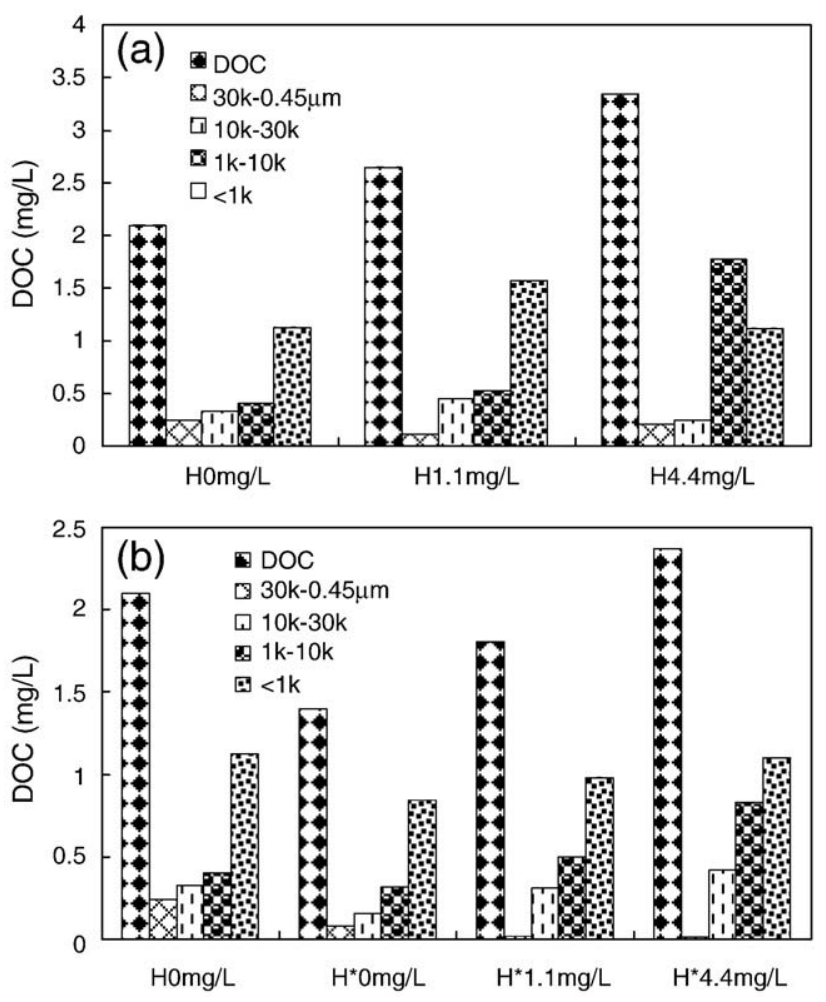

Fig. 3. Apparent molecular weight distributions of MW1 after ozonation and coagulation. $\mathrm{HOmg} / \mathrm{L}, \mathrm{H} 1.1 \mathrm{mg} / \mathrm{L}$ and $\mathrm{H} 4.4 \mathrm{mg} / \mathrm{L}$ represent MW1 samples after pre-ozonation of $\mathrm{O}_{3}$ 0, 1.1 and $4.4 \mathrm{mg} / \mathrm{L}$ respectively. $\mathrm{H}^{*} 0 \mathrm{mg} / \mathrm{L}, \mathrm{H}^{*} 1.1 \mathrm{mg} / \mathrm{L}$ and $\mathrm{H}^{*} 4.4 \mathrm{mg} / \mathrm{L}$ represent MW1 samples after pre-ozonation of $\mathrm{O}_{3} 0,1.1$ and $4.4 \mathrm{mg} / \mathrm{L}$ respectively and coagulation.
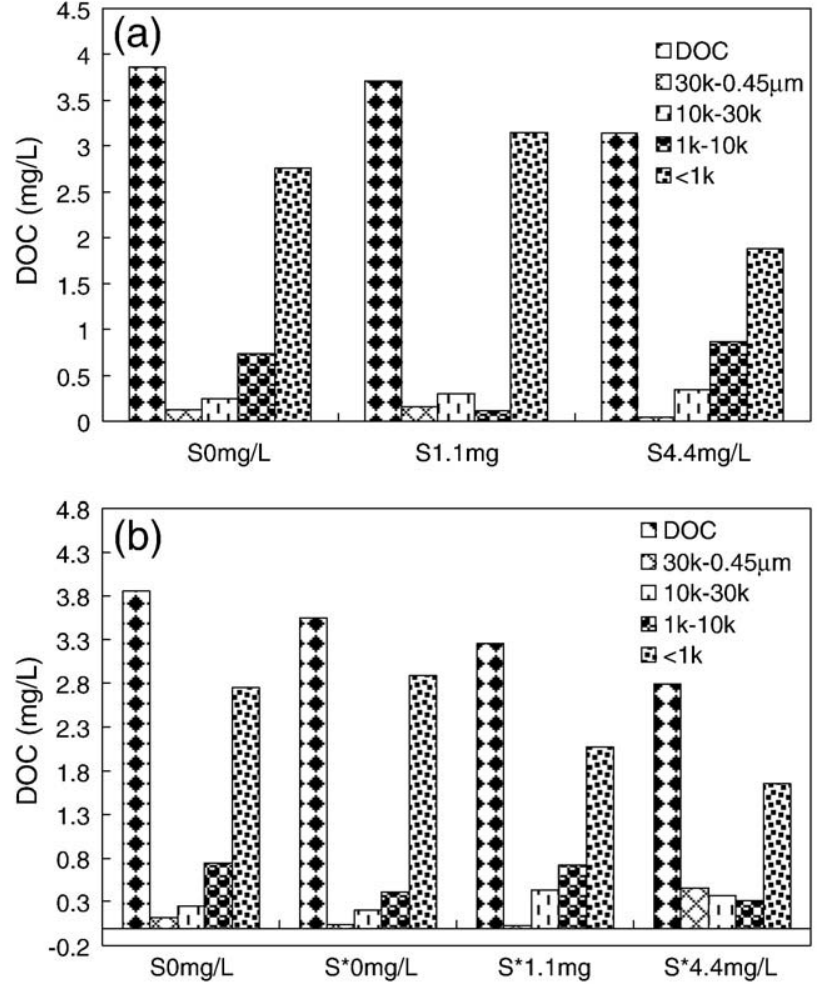

Fig. 4. Apparent molecular weight distributions of MW2 after ozonation and coagulation. S0mg/L, S1.1 mg/L and S4.4 mg/L represent MW2 samples after pre-ozonation of $\mathrm{O}_{3} 0,1.1$ and $4.4 \mathrm{mg} / \mathrm{L}$ respectively. $S^{*} 0 \mathrm{mg} / \mathrm{L}, S^{*} 1.1 \mathrm{mg} / \mathrm{L}$ and $S^{*} 4.4 \mathrm{mg} / \mathrm{L}$ represent MW2 samples after pre-ozonation of $\mathrm{O}_{3} 0,1.1$ and $4.4 \mathrm{mg} / \mathrm{L}$ respectively and coagulation.

(fraction less than $1 \mathrm{kDA}$ ) is the main fraction removed. AOM of other fractions varied somewhat after the combined treatment, which may be caused by the components of the tap water used.
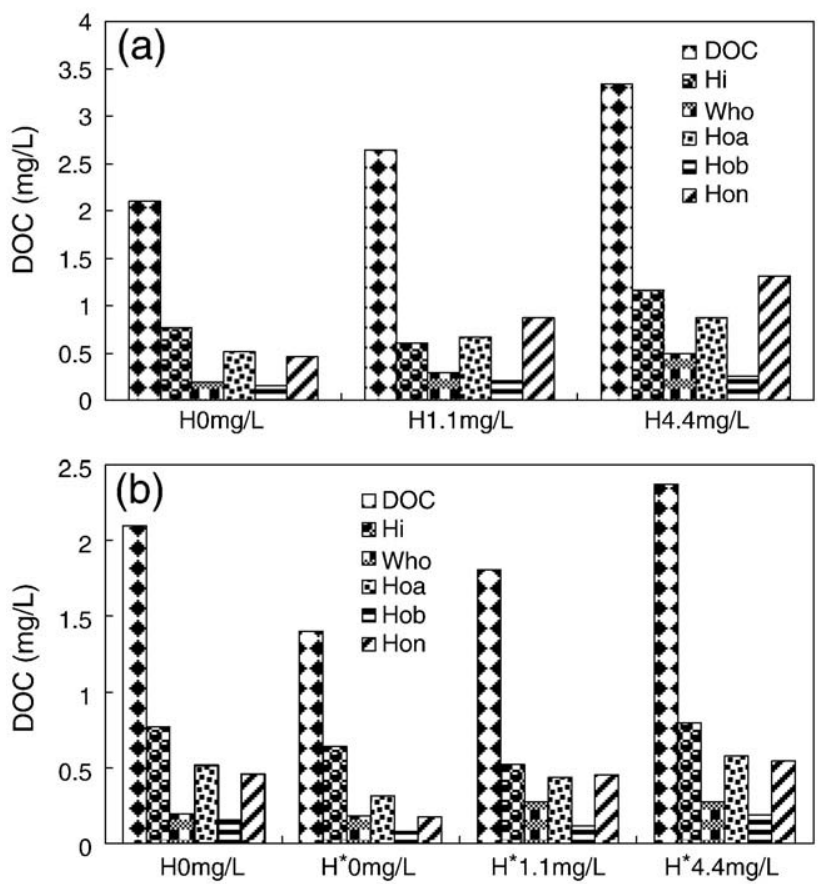

Fig. 5. Resin fractions of MW1 after ozonation and coagulation. H0mg/L, H1.1 mg/L and $\mathrm{H} 4.4 \mathrm{mg} / \mathrm{L}$ represent MW1 samples after pre-ozonation of $\mathrm{O}_{3} 0,1.1$ and $4.4 \mathrm{mg} / \mathrm{L}$ respectively. $\mathrm{H}^{*} 0 \mathrm{mg} / \mathrm{L}, \mathrm{H}^{*} 1.1 \mathrm{mg} / \mathrm{L}$ and $\mathrm{H}^{*} 4.4 \mathrm{mg} / \mathrm{L}$ represent $\mathrm{MW} 1$ samples after preozonation of $\mathrm{O}_{3} 0,1.1$ and $4.4 \mathrm{mg} / \mathrm{L}$ respectively and coagulation. 

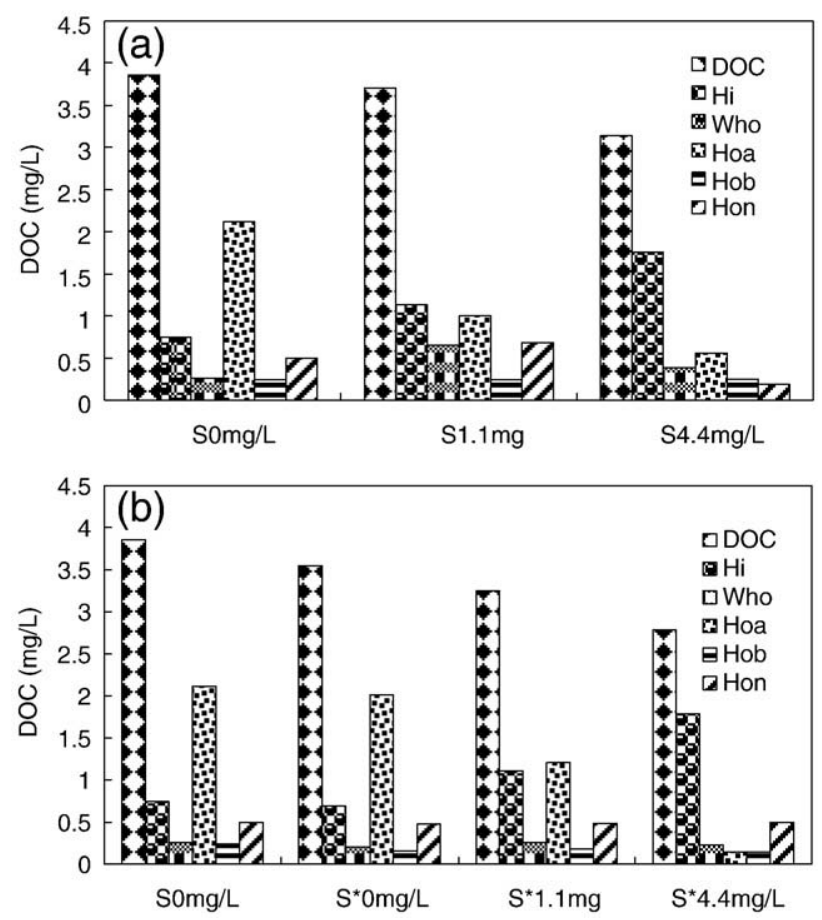

Fig. 6. Resin fractions of MW2 after ozonation and coagulation. S0mg/L, S1.1 mg/L and $\mathrm{S} 4.4 \mathrm{mg} / \mathrm{L}$ represent MW2 samples after pre-ozonation of $\mathrm{O}_{3} 0,1.1$ and $4.4 \mathrm{mg} / \mathrm{L}$ respectively. $\mathrm{S}^{*} 0 \mathrm{mg} / \mathrm{L}, \mathrm{S}^{*} 1.1 \mathrm{mg} / \mathrm{L}$ and $\mathrm{S}^{*} 4.4 \mathrm{mg} / \mathrm{L}$ represent MW2 samples after preozonation of $\mathrm{O}_{3} 0,1.1$ and $4.4 \mathrm{mg} / \mathrm{L}$ respectively and coagulation.

According to Fig. 5, it is clear that almost all fractions of MW1 after ozonation increase to some extent, and the increments grow with increased ozone doses (Fig. 5a). Coagulation without ozonation partly reduces all fractions of AOM. While after ozonation, almost all fractions increased even in moderate ozone dose (Fig. 5b). It could be confirmed that the amount of decomposed or desorbed AOM cannot be removed by coagulation; and for such organic matrix of water, it is unwise to employ pre-ozonation.

It is obvious that smaller molecular and hydrophilic parts of MW1 increase after pre-ozonation. But most of them are not fully removed. It might increase coagulant demand and decrease OM removability via precipitation reactions with coagulants [12,19]. As shown in Table 4, increasing coagulant dosages, turbidities, DOC and $\mathrm{UV}_{254}$ removals are increased significantly under the same conditions.

For MW2 water (Figs. 4,6), the major parts (above $80 \%$ ) of OM are small molecules, salicylic acid, glutamic acid and OMs originated from tap water. OM in MW2 is oxidized and mineralized by $\mathrm{O}_{3}$. Some $\mathrm{OM}$ is fully removed through pre-ozonation. Pre-ozonation plays an effective role in improving coagulation performance. By reducing OM contents and the demand of coagulant, pre-ozonation improved removals of turbidities and DOC. These effects are distinctively enhanced with increasing $\mathrm{O}_{3}$ dosages.

\section{Conclusions}

Besides the guidelines outlined in the Alternative Disinfectants and Oxidants Guidance Manual [22], some principles of ozone application such as organic components in water and points of application were provided in the study.

Results show that impacts of pre-ozonation on coagulation are closely related to AOM characteristics or the basic properties of subject water. Application of pre-ozonation should be based on the AOM present. AOM adsorbed on particles are not adaptive to preozonation, especially if those $\mathrm{OM}$ are sensitive to be decomposed or desorbed to yield smaller and more hydrophilic $\mathrm{OM}$ by $\mathrm{O}_{3}$. $\mathrm{HA}$ as the large molecular parts of NOM is easy to be removed by coagulation. Employing pre-ozonation might impair the whole treatment performance. In this case, the process of ozonation should be placed following coagulation and sedimentation, and combination of $\mathrm{O}_{3}$ and BAC (Biological Activated Carbon) would be more effective, if higher removal of DBP (Disinfection by-products) precursor is required.

Additionally, $\mathrm{O}_{3}$ dose plays a critical role in effects of ozone on coagulation. Overdose of $\mathrm{O}_{3}$ greatly impairs subsequent coagulation.

\section{References}

[1] H. Selcuk, L. Rizzo, A.N. Nikolaou, S. Meric, V. Belgiorno, M. Bekbolet, Desalination 210 (2007) 31-43.

[2] H. Selcuk, Y. Vitosoglu, S. Ozaydin, M. Bekbolet, Desalination 176 (2005) 211-217.

[3] C.N. Chang, Y.S. Ma, F.F. Zing, Chemosphere 46 (2002) 21-30.

[4] P.C. Chiang, E.E. Chang, C.H. Liang, Chemosphere 46 (2002) 929-936.

[5] O.D. Schneider, J.E. Tobiason, JAWWA 92 (10) (2000) 74-87.

[6] S.D. Chang, P.C. Singer, JAWWA 83 (3) (1991) 71-79.

[7] D. Grasso, J. Walter, Jr. Weber, JAWWA 80 (8) (1988) 73-81.

[8] U.V. Gunten, Water Research 37 (7) (2003) 1443-1467.

[9] D.A. Reckhow, P.C. Singer, JAWWA 76 (4) (1984) 151-157.

[10] P.C. Singer, JAWWA 82 (10) (1990) 78-88.

[11] J.E. Tobiason, D.A. Reckhow, J.K. Edzwald, Journal of Water Supply: Research and Technology 44 (1995) 142-150.

[12] M. Edwards, M.M. Benjamin, JAWWA 84 (8) (1992) 63-72.

[13] M. Edwards, M.M. Benjamin, J.E. Tobiason, JAWWA 86 (1) (1994) 105-116

[14] H.L. Liu, D.S. Wang, M. Wang, L. Wang, H.X. Tang, Colloids and Surfaces A: Physicochem. Eng. Aspects 294 (1-3) (2007) 111-116.

[15] K.N. Exall, G.W. Vanloon, JAWWA 92 (11) (2000) 93-102.

[16] D.S. Wang, H.X. Tang, J. Gregory, Environment Science \& Technology 36 (2002) 1815-1820.

[17] H. Bader, J. Hoigné, Water Research 15 (1981) 449-456.

[18] H.W. Walker, M.M. Bob, Water Research 35 (4) (2001) 875-882.

[19] V. Camel, A. Bermond, Water Research 32 (11) (1998) 3208-3222.

[20] M.S. Chandrakanth, G.L. Amy, Environment Science \& Technology 30 (1996) 431-443.

[21] J.K. Edzwald, J.E. Tobiason, Water Science \& Technology 40 (9) (1999) 63-70.

[22] USEPA. Alternative Disinfectants and Oxidants Guidance Manual, Office of Water (4607), EPA 815-R-99-014. http://www.epa.gov/safewater/mdbp/alternative_ disinfectants_guidance.pdf. 1999. 